\title{
Teaching Experience of Sports Anatomy
}

\author{
QI' E Zhu \\ College of Physical Education \\ Hubei University of Science and Technology \\ Xianning,Hubei,China
}

\begin{abstract}
Sports anatomy is a branch of human anatomy,it is a basic compulsory course for all majors which are related to physical education and sports human science in Colleges and Universities.To explore the relationship of human structure and sports action is the main task of this discipline.according to the characteristic of this curriculum and students majoring in physical education,this article points out four teaching experience,they are:Dynamic teaching should be put into use in sports system teaching;there should be more observation and detailed summary in experimental teaching;should pay more attention to link theory with practice in all teaching process,several views about examination.these points are important links to teach this course well.
\end{abstract}

\section{Keywords- Sports Amatomy;Teaching Experience;Dynamic}

\section{INTRODUCTION}

Sports anatomy is a basic compulsory course in Colleges and Universities,it is a theory course,also a experimental course, what is more a application course $^{[1]}$.Sports anatomy belongs to shape science, including a lot of content,involves some rusty terms and abstract concepts, if teachers just teach from theory to theory,it is hard for students to accept.for years, research on teaching method and teaching model haven't achieve any breakthrough.After years of teaching,several experience is pointed out,hopefully,it will improve the teaching effect of sports anatomy.

\section{The TRAit OF Sports ANATOMY AND TEACHING TARGET}

Sports anatomy is on the basis of normal human body structure,research the effect of sports to human body structure and growth,development chiefly. This course has dynamic trait,the dynamic trait is feflected in sports system very obvious,as for this part, "anatomical analysis of sports movement" should be taught under dynamic situation. "dynamic" is the main difference between sports anatomy and human anatomy. The teaching targets of sports anatomy are:to offer anatomy knowledge and theory for sports practice and to prepare for the subsequent courses of sports human science.

\section{TEACHING EXPERIENCE OF SPORTS ANATOMY}

\section{A. "Dynamic" Teaching should be used more in Sports System}

Sports system is the important chapter in sports anatomy,in this part,the main content are "bone" , "joint" , " skeletal muscle" and " anatomical analysis on movement".Among them,joint is the center part,skeletal muscle is the key point,movement analysis is difficulty.Ask students to understand the work feature,work nature and collaborative relationship of skeletal muscle on the basis of grasping the relationship of bone,joint and skeletal muscle, the students could analyze movement from anatomy angle accurately,also could put the theory and method of movement analysis into sports practice freely at the end of this course.easy to see,these content is closely related to sports practice,have strong application,difficult but important.Highlights dynamic feature of sports anatomy,Teachers should use more video to carry out dynamic demonstration, also can find out students volunteers to have human body demonstration, even can try best to develop a model which can fulfill dynamic teaching.In teaching,should avoid be flashy without substance,focus on the form and content of unity,motive students'enthusiasm ${ }^{[2]}$. Because "dynamic teaching” will be very helpful for the teaching effect of this part.

Table1.Example of joint teaching

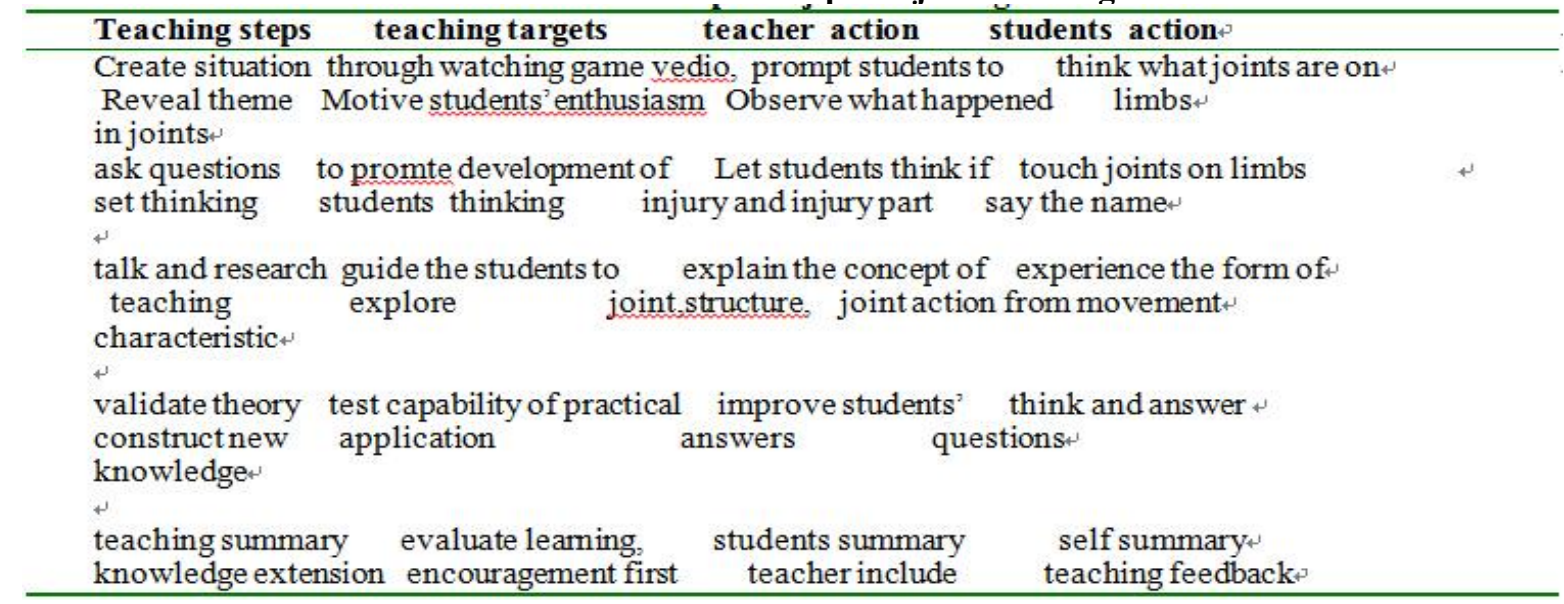




\section{B. There should be more Observation and detailed Summary in experimental Teaching}

Sports anatomy belongs to experimental discipline,the main task in experimental teaching are looking at the model and recognizing the structure,so as to facilitate comprehension and memorization.Because the content which should be observed is much and complicated,so the teachers should be patient and meticulous guidance,refine the important knowledge,also should leave more time for students,Let the students to think more,hands-on,eye movement,observe and summary by themselves.at the end of class,teachers should give chances for students to summary first,because this way can not only encourage them to observe carefully,but also play a good role in training,then teachers give evaluation for students'summary at last,and point essential supplement and emphasis,deepen the grasping of the knowledge again.

\section{The Whole Curriculum should combine theory with practice}

In the movement of the human body,the form,structure and function are complicated,changed and relevant ${ }^{[3]}$.So,we shouldn't treat sports anatomy with static vision,but should pay more attention to link theory with practice in teaching always.Not only put the knowledge into physical education practice,but also apply to practice life,teachers should emphasize the following methods:learning and use of analysis,comprehensive, include.In this way,students can learn in order to practice as a learning principle,regard whether can use as an important scale to test learning levels.

\section{About Examination}

The examination can check not only how the students grasp the knowledge,measure teaching quality,but the examination result can be used as the basis and starting point to improve the teaching quality further.First,proposition should pay attention to students'ability of study,because examination is the feedback of teaching process, if the examination is scientific and reasonable, it will promote other teaching links, if the examination doesn't focus on investigating of study ability.Thus, it will force the students only to pay attention to learn by rote, the high scores is the only thing what students want.While,ignore to develop personal ability in normal times.As in my mind,the examination of sports anatomy should emphasize the following abilities, they are:the ability of recognizing picture and drawing,thinking ability,comprehensive application ability of knowledge,practical ability in experiment.

The examination of sports anatomy should adopt the form of written examination combining of oral examination,for this course belongs to shape science.It will not reflect the learning situation of the students if only through written examination,single written examination has some limitations.In actual teaching,I use this kind of form as oral examination, "looking at the model,recognizing the structure" .During the examination,the teacher can give rhetorical question and question closely, the way of test can urge the students to practise and think more in usual experimental classes, then get a comprehensive grasp of knowledge.

Teachers should organize the students to review before examination.first,guide the students to review systematically,then, guide them to get the knowledge organized and systematic,on the basis of this,teachers should give the collective answer or individual counseling for the questions which are common and representative among the students.As for the review, it is not wise to point out some highlights and column titles.because doing like this will enable the students to have the dependence, do not want to use their brains,it is not good for the students to develop their study ability.

The examination performance should be the comprehensive evaluation of midterm performance and usual performance,we can not take one examination result as the last performance.The usual performance should include attendance,classroom performance,experimental performance,etc.Only through bringing usual performance into the last performance,can the students are promoted to study hard always,also it is helpful for grasping the knowledge firmly and improving the ability strong.

\section{E. Teachers should summary and rethink the teaching always}

For teachers, the teaching process is not only to impart knowledge and skills, what is more to learn,to make progress,to improve oneself for the teachers, is the so-called teaching benefits teachers as well as students.Teachers should summary the good teaching methods,successful cases,also should develop and improve these good experience further,and rethink lesson plan,note,teaching manners,etc,always.This is of great benefit to improve the teaching level,teachers should deal with the relationship between teachers and students,communicate with students in the classroom and outside the classroom, to understand every student,to master their characteristic,it is conductive teach students in accordance with their aptitude.The harmonious relationship between teachers and students can make the interaction between teachers and students more smooth,the degree of students trust the teacher increased,the students would like to be close to the teacher,then, it is advantageous for students to accept teachers'teaching and education,is the so-called "dear teacher to believe its teaching" .

\section{TEACHING MANNERS}

On the basis of the important status of sports anatomy in the whole curriculum system,teachers should do their best in optimizing teaching process and enriching teaching content,only in this way,can promote the students to master the basic knowledge and basic skill effectively,thus, the teaching effect is improved.

\section{INTRODUCTION OF AUTHORS}

QI'E Zhu, College of Physical Education, Hubei University of Science and Technology,

xian ning city, xian an district,yong an road $2 \#, \mathrm{Hu}$ Bei province,437005,Sports Science of Human Body. 


\section{REFERENCES}

[1] SHENG YU Hu Editor in chief.Sports Anatomy[M].BeiJing: People Sports Press, 2000:4

[2] NIAN KUN Zhang.Sports Anatomy Teaching Reform based on double Principle Mode [J].Education and Occupation ,2012,(24):136137

[3] MIN QIN Zou. The Design of moden Teaching of Sports System in Sports Anatomy[J].Journal of Anatomy,2008,(6)876-877 